\title{
Childhood Obesity Research Demonstration (CORD): The Cross-Site Overview and Opportunities for Interventions Addressing Obesity Community-Wide
}

\author{
Jennifer L. Foltz, MD, MPH,',2 Brook Belay, MD, MPH,' Carrie A. Dooyema, MPH, MSN, RN,' \\ Nancy Williams, MSPH, ${ }^{1,2}$ and Heidi M. Blanck, PhD ${ }^{1,2}$
}

\section{Abstract}

Background: This is the first of a set of articles in this issue on the Childhood Obesity Research Demonstration (CORD) project and provides an overview of the multisite approach and community-wide interventions. Innovative multisetting, multilevel approaches that integrate primary healthcare and public health interventions to improve outcomes for children with obesity need to be evaluated. The CORD project aims to improve BMI and obesity-related behaviors among underserved 2- to 12-year-old children by utilizing these approaches.

Methods: The CORD consortium, structure, model terminology and key components, and common measures were solidified in year 1 of the CORD project. Demonstration sites applied the CORD model across communities in years 2 and 3. Evaluation plans for year 4 include site-specific analyses as well as cross-site impact, process, and sustainability evaluations.

Results: The CORD approach resulted in commonalities and differences in participant, intervention, comparison, and outcome elements across sites. Products are to include analytic results as well as cost assessment, lessons learned, tools, and materials.

Discussion: Foreseen opportunities and challenges arise from the similarities and unique aspects across sites. Communities adapted interventions to fit their local context and build on strengths, but, in turn, this flexibility makes cross-site evaluation challenging.

Conclusion: The CORD project represents an evidence-based approach that integrates primary care and public health strategies and evaluates multisetting multilevel interventions, thus adding to the limited research in this field. CORD products will be disseminated to a variety of stakeholders to aid the understanding, prevention, and management of childhood obesity.

\section{Introduction}

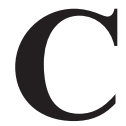
urrently, childhood obesity affects $16.9 \%$ of children ages 2-19 years old in the United States. ${ }^{1}$ Children with obesity are more likely to develop dyslipidemia, type 2 diabetes, fatty liver disease, asthma, and suffer from depression and stigmatization. ${ }^{2-5}$ Childhood obesity is also associated with increased school absenteeism and poorer school performance. ${ }^{6,7}$

The health behavior of children is influenced by factors in multiple environments, including the home, early care and education (ECE), school, community, and healthcare settings. Addressing childhood obesity therefore requires prevention and treatment interventions across settings, programs, and systems. ${ }^{8-10}$ However, few interventions address more than one setting. ${ }^{11,12}$ The Childhood Obesity Research Demonstration (CORD) project, a multifaceted prevention and management effort with three phases spanning 4 years, seeks to fill this research gap. This article outlines the CORD project development and structure, describes the CORD model along with an overview of the interventions and evaluation, provides a comparison of commonalities and differences across the three demonstration sites, and discusses opportunities and challenges to the approach.

A primary goal of CORD is to evaluate a multisetting, multilevel approach that integrates primary care and public

'Division of Nutrition, Physical Activity, and Obesity, National Center for Chronic Disease Prevention and Health Promotion, Centers for Disease Control and Prevention, Atlanta, GA.

${ }^{2}$ U.S. Public Health Service Commissioned Corps, Atlanta, GA. 
health strategies to improve underserved children's health behaviors and ultimately reduce childhood obesity.

\section{Methods}

\section{Development}

The CORD project was authorized through the Children's Health Insurance Program (CHIP) Reauthorization Act in 2009; funding was appropriated by the Affordable Care Act in 2010. CHIP is a low-cost health insurance program for children of working families with limited income. ${ }^{18}$ These children often have higher rates of obesity and less access to care ${ }^{19}$; thus, CORD was to implement and evaluate obesity prevention efforts to improve the health of children ages 2-12 years, who are enrolled in or eligible for CHIP.

CORD grantees were funded through a 4-year cooperative agreement beginning in October 2011. A planning phase took place in year 1 , followed by intervention phases in years 2 and 3 , and an analysis and evaluation phase in year $4 .^{20,21}$

A CORD consortium was developed that consists of stakeholders across sectors and settings that allowed for shared learning, experiences, and resources. CORD is overseen by the CDC by a team approach that included contributions from the CORD lead, scientific advisor, evaluator, and project officer. ${ }^{22}$ The three CORD demonstration sites include the University of Texas Health Science Center, Houston (TX-CORD); San Diego State University (CA-CORD); and the Massachusetts State Department of Health (MA-CORD). The three CORD demonstration sites, in turn, partnered with state and local agencies, community coalitions, ECE centers, school districts, and primary care organizations. An overview of the CORD demonstration sites is provided in Table $1 .{ }^{23-27} \mathrm{~A}$ fourth grantee, the University of Houston, serves as the evaluation and coordinating center (EC-CORD) and provides data warehousing, supports site-specific evaluations, and leads the cross-site evaluation, including a cost analysis. A federal partner steering committee also contributes guidance to the CORD project and includes representatives from the National Institutes of Health, Centers for Medicare and Medicaid Services, Agency for Healthcare Research and Quality, Health Resources and Services Administration, and Administration for Children and Families.

\section{The Childhood Obesity Research Demonstration Project Model}

A common CORD model was used across all demonstration sites. It consisted of interventions in multiple settings that incorporate all levels of the socioecological model $^{9,13}$ to improve behaviors and prevent obesity. Evidence-based interventions for obesity prevention were implemented in each setting that a child encounters, from ECE or schools to their community, healthcare setting, home, and family. The CORD model built on existing state and community efforts to support children's healthy eating, active living, and obesity prevention. Using a collective impact approach focused on integrating primary care and public health, CORD combines changes in preventive care at clinical provider visits with coordinated changes across select ECEs, schools, and community settings. Settings were linked by integrators such as community health workers (CHWs) and community coalitions or community advisory groups. CHWs served in roles of individual- and systems-level coordinated care, providing education and counseling to children and families, helping to link families to resources in their communities, and facilitating community-wide healthy eating and active living.

Interventions were designed for both systems-level (e.g., practices and physical environments of ECE settings) and individual-level change (e.g., changes in child and family behavioral risk factors and BMI). By implementing policy, system, and environmental (PSE) supports in addition to individual-based programs, CORD intends to enhance behavior change and population-level obesity prevention efforts. ${ }^{10,14-17}$ The CORD demonstration sites focused on strategies to improve children's health behaviors by involving the children, parents, and other family members and the communities in which they live. PSE changes were incorporated in ECEs, schools, and healthcare centers, and the hope is that benefits from CORD-initiated interventions may continue after the project evaluation period.

Common terminology was developed for the CORD project and built into the CORD model to help with consistent approaches. The term primary care includes all services delivered and PSE changes made in the healthcare setting. Public health is defined as all services and changes in the ECE, school, and community settings. CHWs deliver services and support system change in both primary care and public health. Primary care services are further defined by a tiered approach. ${ }^{28}$ Primary care plus indicates additional services provided (e.g., intense programs patients are referred to that are based in community centers, Healthy Weight referral clinics, or delivered in family visits) above those provided in a primary care clinic for children who are overweight or obese. Also of note, as a result of ongoing efforts to improve children's health, every community has some degree of obesity prevention efforts occurring at baseline; as such, the comparison groups are termed "no CORD intervention" owing to the fact that the public health and primary care taxonomy here describes the CORD-funded multisetting, multilevel intervention efforts above baseline common practice.

\section{Evaluation Plans}

The CORD project outcomes are similar across sites and include information for site-specific and cross-site evaluations. ${ }^{23,25,27,29}$ Each demonstration site proposed methods to assess outcomes within their site. In addition to sitespecific evaluation, EC-CORD led development of several types of cross-site evaluation plans, including impact, process, and sustainability. The CORD sites and CDC developed common measures and tools during the year 1 


\begin{tabular}{|c|c|c|c|}
\hline CORD project & TX-CORD & CA-CORD & MA-CORD \\
\hline Program name & - Texas CORD & - Our Choice, Nuestra Opción & - Mass in Motion Kids \\
\hline $\begin{array}{l}\text { Cooperative agreement } \\
\text { funded institutions }\end{array}$ & $\begin{array}{l}\text { - The University of Texas Health } \\
\text { Science Center at Houston }\end{array}$ & - San Diego State University & $\begin{array}{l}\text { - Massachusetts State Department } \\
\text { of Public Health }\end{array}$ \\
\hline Brief description $^{a}$ & $\begin{array}{l}\text { - The Texas CORD project in Austin } \\
\text { and Houston, Texas, works within } \\
\text { defined high-needs catchment areas } \\
\text { of both cities to integrate primary } \\
\text { care systems, local YMCAs, ECE } \\
\text { centers and public schools to } \\
\text { deliver prevention. } \\
\text { - Primary prevention interventions } \\
\text { are delivered in the community } \\
\text { over a 2-year time period. } \\
\text { - The TX-CORD intervention site } \\
\text { has a secondary prevention } \\
\text { randomized trial (only children with } \\
\text { BMI > 85th percentile) embedded } \\
\text { within the community approach. } \\
\text { It compares an enhanced primary } \\
\text { care approach to an intensive } \\
\text { I-year behavioral modification } \\
\text { program in the YMCAs. }\end{array}$ & $\begin{array}{l}\text { - The Our Choice/Nuestra Opción } \\
\text { project in Brawley, El Centro, and } \\
\text { Calexico, California, represents } \\
\text { a newly formed collaborative } \\
\text { comprising a research institute, } \\
\text { a federally qualified health center } \\
\text { (Clinicas), a county public health } \\
\text { department, ECE centers, public } \\
\text { schools, local recreation } \\
\text { departments and agencies, } \\
\text { and restaurants. } \\
\text { - This study implements varying } \\
\text { combinations of intervention } \\
\text { activities across two cities to } \\
\text { compare the relative effects of an } \\
\text { integrated primary care and public } \\
\text { health, primary care alone, and } \\
\text { public health alone approaches to } \\
\text { a control condition located } \\
\text { in the third city. }\end{array}$ & $\begin{array}{l}\text { - The Mass in Motion Kids project } \\
\text { in Fitchburg and New Bedford, } \\
\text { Massachusetts, builds on an } \\
\text { existing state department of } \\
\text { public health program, Mass in } \\
\text { Motion, by enhancing systems and } \\
\text { practices of primary care services } \\
\text { in federally qualified healthcare } \\
\text { centers, WIC facilities, ECE } \\
\text { centers, public schools and } \\
\text { associated afterschool programs, } \\
\text { and community-specific media } \\
\text { activities. } \\
\text { - A subset of the children with } \\
\text { BMI > 85th percentile in the } \\
\text { MA-CORD intervention group } \\
\text { will receive an enhanced primary } \\
\text { care approach in a healthy weight } \\
\text { clinic. }\end{array}$ \\
\hline $\begin{array}{l}\text { Community } \\
\text { demographics }\end{array}$ & $\begin{array}{l}\text { - }>50 \% \text { students in catchment areas } \\
\text { on assisted lunch program } \\
\text { - 19\% of preschoolers and } 35 \% \text { of } \\
\text { fifth graders are obese } \\
\text { - Largely recent immigrant parents } \\
\text { from Mexico and other Latin } \\
\text { American countries }\end{array}$ & $\begin{array}{l}\text { - } 23 \% \text { of children below poverty line } \\
\text { - } 47 \% \text { of children in county } \\
\text { overweight or obese } \\
\text { - Immigrant populations from } \\
\text { Mexico }\end{array}$ & $\begin{array}{l}\text { - } 24-27 \% \text { of children below poverty } \\
\text { line in intervention cities } \\
\text { - 40\% of children overweight } \\
\text { or obese in intervention cities } \\
\text { - Immigrant populations from } \\
\text { Portugal and West Africa }\end{array}$ \\
\hline Inclusion criteria & $\begin{array}{l}\text { - Child, ages } 2-12 \text { years } \\
\text { - BMI } \geq 85 \text { th percentile for } \\
\text { randomized trial }\end{array}$ & $\begin{array}{l}\text { - Child, ages 2-II at baseline } \\
\text { - No BMI criteria for sample }\end{array}$ & $\begin{array}{l}\text { - Child, ages } 2-12 \text { years } \\
\text { BMI } \geq 85 \text { th percentile for healthy } \\
\text { weight clinic }\end{array}$ \\
\hline $\mathrm{CHW}$ component & $\begin{array}{l}\text { - CHWs are based in the community } \\
\text { setting and their role includes that } \\
\text { of counselors at community } \\
\text { organizations and assisting in } \\
\text { delivery of packaged wellness } \\
\text { programs for secondary } \\
\text { prevention. }\end{array}$ & $\begin{array}{l}\text { - CHWs are based in the healthcare } \\
\text { setting and their roles include } \\
\text { conducting a family wellness } \\
\text { program, serving as part of an } \\
\text { obesity care team, and serving on } \\
\text { various committees for policy and } \\
\text { system changes. }\end{array}$ & $\begin{array}{l}\text { CHWs are based in the healthcare } \\
\text { setting and they serve as wellness } \\
\text { navigators with educational and } \\
\text { community involvement roles. }\end{array}$ \\
\hline
\end{tabular}

anterventions promote healthy eating, active living, and obesity prevention and control by using multisetting, multilevel approaches that address policy, system, and environment changes as well as individual and family counseling and behavior change.

CORD, the Childhood Obesity Research Demonstration (CORD) project; CHW, community health worker; ECE, early care and education; WIC, Special Supplemental Nutrition Program for Women, Infants, and Children.

planning phase to facilitate analysis of these outcomes across sites.

The impact evaluation was developed to examine the following research question: Does the CORD model of bridging primary care and public health with multisetting, multilevel interventions linked by CHWs affect children's behaviors, their BMI, and other measures? The main outcomes are assessment of BMI and behaviors, including increasing fruit, vegetable, and water consumption; increasing physical activity; decreasing sugary drinks and energy-dense foods; decreasing screen time; and increas- ing quality sleep. Additional common outcomes include satisfaction with care, quality of life, and parenting skills. A set of 35 common measures will be used for the impact evaluation and allow for a uniform way to assess child/ family sociodemographic characteristics and common outcomes of CORD. The questions come from validated instruments. Common PSE tools are also used in 103 schools, 90 ECEs, 17 healthcare settings, and in the communities. The PSE measures come from instruments such as the Nutrition and Physical Activity Self-Assessment for Child Care Tool ${ }^{30}$ used in the ECE setting and the Wilder 
Table 2. A Comparison of Characteristics From the Three CORD Demonstration Sites ${ }^{23-27}$

Data/design elements

Commonalities across sites

Differences between sites

Participants

\begin{tabular}{|l|l|l}
\hline Population characteristics & $\begin{array}{l}\text { - High proportion low income, CHIP eligible } \\
\text { - High rates of obesity } \\
- \text { 2- to I2-year-old children }\end{array}$ & $\begin{array}{l}\bullet \text { Race/ethnic composition } \\
\text { Geographic location }\end{array}$ \\
\hline Participants inclusion criteria & $\begin{array}{l}\text { - All sites have children } \geq 85 \text { th percentile of BMI } \\
\text { as part of the sample }\end{array}$ & $\bullet$ BMI percentile cutoff for sample inclusion varies \\
\hline Participant sampling & $\begin{array}{l}\text { - Intervention and comparison participants } \\
\text { are drawn from populations with similar } \\
\text { sociodemographic characteristics }\end{array}$ & $\begin{array}{l}\text { Recruitment occurs in different settings } \\
\text { (community and/or clinic recruitment). }\end{array}$ \\
\hline
\end{tabular}

Interventions

Intervention framework $\quad$ - Multisetting, multilevel interventions: All include interventions in ECE, schools, healthcare, and the community targeting individual and family behavior change as well as PSE changes

- Cross-setting linkages (e.g., CHW, coalitions)

Strategies $\quad$ - Increase fruit and vegetable consumption, water intake, and physical activity and improve sleep

Decrease fatty foods, sugar drink intake, and

screen time

\begin{tabular}{|c|c|c|}
\hline Consortium & $\begin{array}{l}\text { Partners composed of public health department, } \\
\text { academic center, and partnerships across settings } \\
\text { and sectors }\end{array}$ & - Sites have various additional partners \\
\hline $\mathrm{CHW}$ & $\begin{array}{l}\text { - Integrate across settings } \\
\text { - Overarching activities similar }\end{array}$ & $\begin{array}{l}\text { - Primary setting base (e.g., clinic, community) } \\
\text { - Specific tasks (e.g., counseling, case management) }\end{array}$ \\
\hline Capacity & $\begin{array}{l}\text { - All are designed to take evidence-based } \\
\text { interventions and build on community capacity. } \\
\text { - All allow for additional supports to be leveraged } \\
\text { by the CORD intervention }\end{array}$ & $\begin{array}{l}\text { - Capacities differ by community } \\
\text { - Additional supports leveraged differ by community } \\
\text { (e.g., awards of additional grants) }\end{array}$ \\
\hline \multicolumn{3}{|l|}{ Comparisons } \\
\hline Catchment areas & $\begin{array}{l}\text { - All sites selected a comparison community with } \\
\text { similar sociodemographic characteristics, but } \\
\text { were not supported with CORD multisetting, } \\
\text { multilevel interventions }\end{array}$ & $\begin{array}{l}\text { - Catchment community geographical boundaries } \\
\text { vary } \\
\circ \text { Comparison area within the same city } \\
\text { as intervention area } \\
\text { Comparison city within the same county } \\
\text { as intervention city } \\
\text { Comparison city within the same state } \\
\text { as intervention city }\end{array}$ \\
\hline Groups & $\begin{array}{l}\text { - All sites include groups of full CORD intervention } \\
\text { components (public health and primary care plus) }\end{array}$ & $\begin{array}{l}\text { - Sites also include one or two comparison groups } \\
\text { of partial intervention components (public health } \\
\text { and primary care; public health; primary care plus) }\end{array}$ \\
\hline
\end{tabular}

\section{Outcomes}

Data type, cohort

- Longitudinal outcome data are gathered on parents and children in primary intervention groups

\begin{tabular}{l|l}
\hline Design & - Quasi-experimental \\
\hline Timing & $\begin{array}{l}\text { - Two years of intervention activities } \\
\text { - All include clinical data collected at } 0 \text { and } 12 \\
\text { months }\end{array}$ \\
\hline
\end{tabular}

- Specific strategies to accomplish overarching strategic goals differ by site

- Specific interventions differ by site

- Sites have various additional partners

- Primary setting base (e.g., clinic, community)

anagement)

Additional supports leveraged differ by community (e.g., awards of additional grants)

Catchment community geographical boundaries

Comparison area within the same city as intervention city Comparison city within the same state intervention city of partial intervention components (public health primary care; public health; primary care plus)

A mix of longitudinal, cross-sectional data are collected in comparison groups

- Some subgroups are matched or randomized

- Intensity differs at different points in the interventions

- Sites have additional measurement time points from data derived in clinical and public health settings 


\begin{tabular}{|c|c|c|}
\hline Data/design elements & Commonalities across sites & Differences between sites \\
\hline Measures & $\begin{array}{l}\text { - Common outcome measures for individuals } \\
\text { - Weight-related changes: height, weight, BMI } \\
\text { - Sociodemographics } \\
\text { - Behaviors } \\
\text { - Fruit and vegetable consumption } \\
\text { - Sugary beverage consumption } \\
\text { - Water consumption } \\
\text { - Physical activity } \\
\text { - Screen time } \\
\text { - Sleep time } \\
\text { Quality of life } \\
\text { - Parenting strategies } \\
\text { - Satisfaction with healthcare } \\
\text { Common outcome tools for populations } \\
\text { PSE-level measures in all settings }\end{array}$ & $\begin{array}{l}\text { - Site-specific measures assess elements unique } \\
\text { to each site and provide additional insights } \\
\text { on interventions. }\end{array}$ \\
\hline CORD products & $\begin{array}{l}\text { - Cross-site evaluations including impact, process, } \\
\text { sustainability, cost, and success stories }\end{array}$ & - Site-specific evaluations, toolkits, and materials \\
\hline
\end{tabular}

CORD, the Childhood Obesity Research Demonstration (CORD) project; CHIP, Children's Health Insurance Program; CHW, community health worker; ECE, early care and education; PSE, policy, systems, and environment.

Collaboration Factors Inventory Survey ${ }^{31}$ for community coalitions. In instances where different assessment tools are used across sites (e.g., a community has invested in an existing tool), then common activities or constructs that are key to the CORD model (as described above) are measured to capture similar content.

The process evaluation defines the reach of intervention activities, describes program training and education materials, and documents PSE changes. The approach captures dose delivered and fidelity at two levels: demonstration site investigators to providers (e.g., healthcare providers, ECE providers, and teachers) and providers to families. Process data are obtained, for example, from administrative data and surveys, CHW iPad quantitative data collection applications, and qualitative interviews.

The third type of cross-site evaluation focuses on sustainability. This assesses the potential for continuation of intervention activities and benefits past the project's completion. It documents the institutionalization and standardizing of new practices in each setting and describes what will be needed to maintain community capacity to continue these efforts. This evaluation also includes identifying components needed to replicate the CORD model in other communities.

\section{Results}

\section{Commonalities and Differences}

The CORD project will describe three demonstration experiences applying the CORD model with common key components for obesity prevention and management. It will be evaluated using common measures, tools, and terminology.
Although the CORD model is the same in all three demonstration sites, it is not a fixed protocol. As such, demonstration sites contain differences in participants, interventions, comparison groups, and outcomes (Table 2). For example, participants are demographically diverse across the sites and participants were recruited from either the clinic or community or both. The individualized interventions vary in specified tasks for CHWs, specific strategies and approach to the overarching cross-site obesity prevention and management goals, and comparison groups also vary by demonstration site. For the geographical recruitment areas, MA-CORD has two intervention cities and a comparison city within the same state. In CA-CORD, a comparison city is within the same county, and in TX-CORD, the comparison groups are closest geographically with comparison catchment areas within the same cities. The intervention groups include communities receiving the full CORD intervention (public health and primary care plus), and comparison groups are those with partial intervention components (public health and primary care, public health, or primary care plus) and those receiving no CORD intervention. Some site-specific differences exist in study design (e.g., experimental design in the TX-CORD secondary prevention group), data type (e.g., longitudinal data in the four CACORD comparison groups), and measures (e.g., MA-CORD collects additional Special Supplemental Nutrition Program for Women, Infants, and Children [WIC] data), and timing of data collection. These variations in addressing the overarching research question provide unique perspectives as a result. More detailed information on the populations, interventions, and evaluation elements is provided in the accompanying articles in this supplement. ${ }^{23-27,29}$ 
The resulting series of CORD products will have a common cross-site evaluation, detailed different sitespecific findings, and a set of recommendations and lessons learned. Other items include collection of success stories by a standard form, consistent cross-site collection of detailed cost information (e.g., training providers, delivering interventions in each setting, and supply of equipment), and a number of products created by demonstration sites, such as posters, booklets, toolkits, and educational handouts. If CORD interventions are found to be effective, the findings could be translated into practice and packaged as program and PSE changes to be implemented and adapted by other communities and brought to scale.

\section{Discussion}

CORD is a research demonstration project that offers unique opportunities. First, in light of the paucity of findings on obesity changes in communities targeting more than two settings across levels of the socioecological model, CORD represents an opportunity to test an integrated model of primary care and public health interventions in three demonstration sites and enhance understanding in this scientific field. This model also includes both primary prevention approaches to benefit all children and secondary treatment intervention components. This approach allows for evaluation of the integrated strategy for reduction of adiposity among overweight and obese children through treatment interventions embedded within beneficial community supports. For healthy weight children, the primary prevention strategies aim to prevent the onset of obesity.

CORD research provides the opportunity to assess three approaches to including CHWs in the team for coordinated obesity prevention and treatment. They served in varying roles, including as patient navigators of the health system, health educators (e.g., teaching cooking classes and parenting practices), counselors, and trainers.

As another distinctive element of this project, the design of CORD includes a set of complementary interventions adapted to the unique needs of each CORD community with ongoing feedback from community advisory groups. This flexibility allows interventions to build on local capacity (i.e., community based) and may be useful for decreasing implementation costs and improving sustainability of the intervention.

CORD allowed the opportunity for preplanning to refine the CORD model and a set of specific common measures to be captured by each demonstration site. This allowed for more similarities in measures and design elements among the sites. This may aid our understanding of key components of the model.

Finally, the CORD project offers the opportunity for sharing products, such as tools that have potential to advance best-practice team approaches and study evaluations. Products also include CORD materials that can inform programs, policies, systems, and environments supportive of children, families, providers, and communities.
Conversely, many of the same CORD characteristics that lead to opportunities also bring challenges. One of CORD's greatest challenges arises from allowing for flexibility in design given that differences across the demonstration sites are expected to create some difficulties in the cross-site evaluation. Also, though external validity arising from evaluations of natural environments is higher, this is achieved at the trade-off of lower internal validity given that unmeasured confounders may not be randomly distributed. In addition, challenges are faced owing to the complexity of the CORD intervention to address a multifactorial chronic disease. Evaluating such complex interventions can require thinking beyond conventional trials. ${ }^{32}$ CORD interventions, though complex in examining coordinated, community-wide, multisetting, multilevel interventions with linkages across sectors, hope to add insights on solutions for obesity prevention and management. The CORD project may not lead to generalizable results to all US communities based on limiting the project to three sites. For example, the data may be less generalizable to Native American communities.

\section{Conclusion}

In summary, CORD has a common model of integrated primary care and public health with multisetting, multilevel interventions linked by CHWs. A consortium of experts, institutions, and agencies are working together to deliver individualized interventions that build on community capacity and community advisor input in order to improve care and obesity-related outcomes for high-risk children. The project has a set of common measures, terminology, and a cross-site evaluation plan. The products from the CORD evaluations will be disseminated to a variety of stakeholders.

\section{Acknowledgments}

The authors acknowledge all the investigators and collaborators at MA-CORD, CA-CORD, TX-CORD, and ECCORD. The authors also acknowledge Suzianne Garner at CDC, CDC subject matter experts, the CORD Federal Steering Committee, and the efforts across stakeholders and families. The findings and conclusions in this report are those of the authors and do not necessarily represent the official position of the CDC.

\section{Author Disclosure Statement}

No competing financial interests exist.

\section{References}

1. Ogden CL, Carroll MD, Flegal KM. Prevalence of childhood and adult obesity in the United States, 2011-2012. JAMA 2014;311: 806-314. 
2. Freedman DS, Mei Z, Srinivasan SR, et al. Cardiovascular risk factors and excess adiposity among overweight children and adolescents: The Bogalusa Heart Study. J Pediatr 2007;150:12-17.

3. Daniels SR, Arnett DK, Eckel RH, et al. Overweight in children and adolescents: Pathophysiology, consequences, prevention, and treatment. Circulation 2005;111:1999-2002.

4. Bazargan-Hejzani S, Alvarez G, Teklehaimanot S, et al. Prevalence of depression symptoms among adolescents aged 12-17 years in California and the role of overweight as a risk factor. Ethn Dis 2010;20:S107-S115.

5. Schwartz MB, Puhl R. Childhood obesity: A societal problem to solve. Obes Rev 2003;4:57-71.

6. Geier AB, Foster GD, Womble LG, et al. The relationship between relative weight and school attendance among elementary schoolchildren. Obesity 2007;15:2157-2161.

7. Taras H, Potts-Datema W. Obesity and student performance at school. J Sch Health 2005;75:291-295.

8. Institute of Medicine. Bridging the Evidence Gap in Obesity Prevention: A Framework to Inform Decision Making. The National Academies Press: Washington, DC, 2010.

9. Story M, Kaphingst KM, Robinson-O'Brien R, et al. Creating healthy food and eating environments: Policy and environmental approaches. Annu Rev Public Health 2008;29:253-272.

10. Swinburn BA, Sacks G, Hall KD, et al. The global obesity pandemic: Shaped by global drivers and local environments. Lancet 2011;378:804-814.

11. Bleich SN, Segal J, Wu Y, et al. Systematic review of communitybased childhood obesity prevention studies. Pediatrics 2013;132: e201-e210.

12. Wang Y, Wu Y, Wilson RF, et al. Childhood obesity prevention programs: Comparative effectiveness review and meta-analysis. Comparative Effectiveness Review No. 115. (Prepared by Johns Hopkins University, contract no. 290-2007-10061-I.) AHRQ publication no. 13-EHC081-EF. Agency for Healthcare Research and Quality: Rockville, MD, 2013.

13. Institute of Medicine Committee on Prevention of Obesity in Children and Youth. Preventing Childhood Obesity: Health in the Balance. The National Academies Press: Washington, DC, 2005.

14. Foltz JL, May AL, Belay B, et al. Population-level intervention strategies and examples for obesity prevention in children. Annu Rev Nutr 2012;32:391-415.

15. Institute of Medicine. Legal Strategies in Childhood Obesity Prevention: Workshop Summary. The National Academies Press: Washington, DC, 2011.

16. Waters E, de Silva-Sanigorski A, Hall BJ, et al. Interventions for preventing obesity in children. Cochrane Database Syst Rev 2011; 12:CD001871.

17. Dietz W, Lee J, Wechsler H, et al. Health plans' role in preventing overweight in children and adolescents. Health Affairs 2007;26: $430-440$.

18. The Henry J. Kaiser Family Foundation. Medicaid and the uninsured: Children's Health Insurance Program Reauthorization Act of 2009 (CHIPRA). Available at www.kff.org/medicaid/upload/ 7863.pdf Last accessed November 21, 2014.

19. Wang Y. Cross-national comparison of childhood obesity: The epidemic and the relationship between obesity and socioeconomic status. Int J Epidemiol 2001;30:1129-1136.

20. US Department of Health and Human Services. Affordable Care Act (ACA): Childhood Obesity Research Demonstration Funding Opportunity Announcement (RFA-DP-11-007). 2011. Available at www.grants.gov/web/grants/search-grants.html Last accessed November 21, 2014

21. Dooyema CA, Belay B, Foltz JL, et al. The Childhood Obesity Research Demonstration project: A comprehensive community approach to reduce childhood obesity. Child Obes 2013;9:454459.

22. Williams NA, Dooyema CA, Foltz JL, et al. The Childhood Obesity Research Demonstration (CDC-CORD) project: A team approach for supporting a multisite, multisector intervention. Child Obes 2015;11:104-108.

23. Hoelscher DM, Butte NF, Barlow S, et al. A systems approach to childhood obesity prevention and treatment: The Texas Child Obesity Research Demonstration (TX-CORD) project. Child Obes 2015;11:71-91.

24. Oluyomi AO, Byars A, Byrd-Williams C, et al. A geographical information science (GIS) approach to conducting area-level comparative analysis of study areas in the Texas Childhood Obesity Research Demonstration (TX_CORD) project. Child Obes 2015;11:58-70.

25. Ayala GX, Ibarra L, Binggeli-Vallarta A, et al. Our Choice/ Nuestra Opción: the Imperial County, California Childhood Obesity Research Demonstration study (CA-CORD). Child Obes 2015; 11:37-47.

26. Taveras EM, Blaine RE, Davison KK, et al. Design of the Mass in Motion Kids Childhood Obesity Research Demonstration (MACORD) study. Child Obes 2015;11:11-22.

27. Davison KK, Falbe J, Taveras EM, et al. Evaluation overview for the Mass in Motion Kids Childhood Obesity Research Demonstration (CORD) study. Child Obes 2015;11:23-36.

28. Barlow SE, and the Expert Committee. Expert Committee recommendations regarding the prevention, assessment, and treatment of child and adolescent overweight and obesity: Summary report. Pediatrics 2007;120:S164-S192.

29. O'Connor DP, Lee RE, Mehta P, et al. Childhood Obesity Research Demonstration (CORD) project: Cross-site evaluation methods. Child Obes 2015;11:92-103.

30. Ward DS, Benjamin SE, Ammerman AS, et al. Nutrition and physical activity in child care: Results from an environmental intervention. Am J Prev Med 2008;35:352-356.

31. Wilder Collaboration Factors Inventory Survey. Available at www .wilder.org/Wilder-Research/Research-Services/Pages/WilderCollaboration-Factors-Inventory.aspx Last accessed November 21, 2014.

32. Victoria CG, Habicht JP, Bryce J. Evidence-based public health: Moving beyond randomized trials. Am J Public Health 2004;94: 400-405.

Address correspondence to:

Jennifer L. Foltz, MD, MPH

Division of Nutrition, Physical Activity, and Obesity National Center for Chronic Disease Prevention and Health Promotion Centers for Disease Control and Prevention 4770 Buford Highway Northeast $M S$ F-77 Atlanta, GA 30341

E-mail: jfoltz@cdc.gov 